\title{
«Patient» oder «Kunde»
}

\section{Rolf H. Adler}

Prof. em., Dr. med., ehem. Chefarzt Innere Medizin, C.-L.-Lory-Haus, Inselspital Bern

Im Protokoll der SGAIM-Qualitätskommission vom 17.12.2017 wird der Patient zum Kunden. Darüber habe ich mich aufgehalten und einen Leserbrief geschrieben [1]. Der Präsident der Qualitäts-Kommission hat eine Replik verfasst, bei der mir unklar bleibt, warum er an der Ersetzung des Begriffs «Patient» durch «Kunde» festhält [2]. Kunde wirkt harmlos, verbirgt aber einen tiefgreifenden Wandel in der heutigen Medizin, der dem ärztlichen Beruf und den Patienten zum Schaden gereichen wird.

\section{Zwei Geschichten}

Ich versuche die Klärung des Unterschieds zwischen Patient und Kunde anhand zweier selbsterlebter Geschehnisse. Im Sommer 2017 verbrachte unsere Familie einige Tage mit Freunden. Deren Tochter trug einen Kaftan, eine Art Überwurfkleid. Es gefiel meiner Frau. Nach unserer Rückkehr blätterte sie in einem ModeKatalog, entdeckte einen Kaftan und bestellte ihn online.

Im Frühling 2016 liess ich das Stethoskop bei einem Hausbesuch liegen. Zuhause holte ich ein altes hervor. Um seine Qualität zu prüfen, setzte ich es am Erb'schen Punkt auf. Zuerst staunte und dann erschrak ich: Ich hörte ein 5/6 lautes, hochfrequentes, holosystolisches Decrescendo-Geräusch bis in die vordere Axillarlinie. Gleichentags bestätigte meine Praxiskollegin meinen Verdacht einer Mitralklappeninsuffizienz und meldete mich bei einem Kardiologen an. Es stellte sich heraus, dass er und mein Sohn zusammen bergsteigen. Das gab mir ein gutes Gefühl. Dennoch beunruhigte mich der Bescheid einer schweren Klappeninsuffizienz mit leicht erweitertem linken Vorhof. Der Arzt erlaubte mir jede sportliche Betätigung und gab mir einen Kontroll-Termin in sechs Monaten. Ich blieb symptomfrei und machte mit meiner Familie einige Bergtouren. Bei einem Mittagessen mit meinem früheren Chef erzählte ich ihm von meinem kardialen Problem. Er riet mir von Anstrengungen ab. Die zwei Meinungen verunsicherten. Der Herzchirurg nahm sich Zeit und bekräftigte die Beurteilung durch den Kardiologen. Einen Operationstermin festzulegen hielt er für verfrüht. Es gebe Algorithmen für die Indikation, im Einzelfall hülfen sie nicht. In den Jahren 2000 und 2002 machte ich eine Pericarditis durch. Die
Echokardiografien waren damals in Bezug auf die Klappen unauffällig.

\section{Reaktionen von Kundin und Patient}

Meine Frau als Kundin: Gefallen am Kaftan-Vorfreudeanregende Suche-Finden eines Kaftans - freiwilliger Kauf ohne Kontakt zu einer Verkäuferin - Kaftan von Freundin gekürzt ohne nachteilige Folgen für das Kleidungsstück.

Ich als Patient: Diagnose einer schweren Mitralklappeninsuffizienz - Staunen, Schreck, Unsicherheit - gezwungen, Hausärztin beizuziehen - Einwilligen in die kardiologischen Untersuchung - gespanntes Erwarten der Diagnose - weitgehendes Vertrauen in den Arztdennoch banges Warten auf das Konsilium beim Herzchirurgen - Unsicherheit, weil Zeitpunkt für eine Operation nicht gegeben werden kann - Vorschlag der Kontrolle in sechs Monaten - fast tägliches Prüfen der Regelmässigkeit des Pulses und ob sich beim Nordic Walking auf vertrauten Wegen erschwertes Atmen einstelle.

\section{Vergleich zwischen Patient und Kundin}

Die Kundin wählt den Zeitpunkt und Kauf ohne Bedrängnis. Der Patient wird durch die Entgleisung seines psychischen und körperlichen Gleichgewichts zum Handeln gezwungen. Entzöge er sich dem Zwang, würde er sich selbst schädigen. Die Kundin fühlt Freude, der Patient Bedrohung, Angst, Unsicherheit. Die Kundin kann Ort und Zeit, sowie den Gegenstand frei und unbeschwert wählen, und auf eine Verkäuferin verzichten. Der Patient vermag Arzt und Zeitpunkt der Abklärung nur ganz beschränkt mitbestimmen. Er 
wird abhängig. Der Kaftan erleidet durch die Kürzung keinen Schaden. Der Patient muss Folgen einer Herzoperation in Kauf nehmen. Die Kundin bleibt seelisch im Gleichgewicht. Der Patient erlebt episodisch Angst, Unsicherheit, ja sogar den Gedanken, nach einem Eingriff invalid zu werden.

\section{Ursachen für die Bezeichnung des Patienten als Kunde}

Es gibt zwei Gründe für das Ersetzen von Patient durch Kunde. Einmal die Einführung von Physik und Chemie als Basis in die Medizin. Als Beleg dafür steht die Aussage von zwei bedeutenden Forschern im 19. Jahrhundert: Von Brücke und Du Bois-Reymond schrieben sich auf ihre Fahne, dass sie nicht eher ruhen wollten, als bis das lebende System Mensch vollständig physikalisch-chemisch erklärt ist.

Dazu ein Beispiel: Die Auskultation des Herzens musste während meiner Assistentenzeit in der Inneren Medizin mit dem Stethoskop mühsam erlernt werden. Neuerdings gibt es ein solches Instrument, das man in der Herzgegend aufsetzt. Es überträgt die akustischen Phänomene besser, zeichnet sie auf, leitet sie weiter an ein Zentrum, wo die Diagnose gestellt und dem Arzt gemeldet wird. Im Gebiet der Medizin gibt es eine Vielzahl ähnlicher technischer Fortschritte. Sie erlauben es dem Arzt, eine grosse Menge von Daten zu sammeln und aus ihnen Diagnosen und Therapien abzuleiten, ohne mit dem Kranken in echten Kontakt zu treten.

Die Gefahren solchen Vorgehens haben eminente Ärzte schon früh im 20. Jahrhundert erfasst. So mahnte Harvey Cushing, Neurochirurg, dass der Arzt nicht nur die Krankheit, sondern den Patienten mit der Krankheit, und nicht nur diese beiden, sondern Krankheit und Patient in seiner Umwelt zu erfassen hat, und Francis Peabody betonte, "the secret of the care of the patient is in caring for the patient".

Dazu ein Beispiel: Eine 50-jährige Frau ruft ihre Krankenkasse an, weil sie gemäss Vertrag vorher keinen Arzt aufsuchen darf. Sie hat Druckgefühle auf der Brust. Sie fragt, ob sie zu ihrem Hausarzt gehen dürfe, der nebenan wohnt und praktiziert. Die Auskunftsperson besteht darauf, dass eine Ambulanz sie abhole und ins Bezirksspital bringe. Dort wird sie untersucht, EKG und Echokardiogramm sowie die Herzenzyme sind normal. Weil ihre Mutter etwa im gleichen Alter angeblich an einem Herzinfarkt verstorben ist, wird sie in die 50 km entfernte kardiologische Uni-Klinik transportiert. Die eingehende Untersuchung, eingeschlossen eine Coronarangiografie schliesst eine Erkrankung des Herzens aus. Psychixch sei die Frau nicht auffällig.
Der Hausarzt erfährt einige Tage später von der Patientin, dass sie seit drei Monaaten sehr schlecht schlafe, weil sie seelisch belastet sei.

Dann die zweite Komponente: Der Arzt , beziehungsweise die vielen Ärzte, die beim einzelnen Patienten beigezogen werden, vermögen aus Zeitgründen keine fundierte Anamnese mehr aufzunehmen, denn das ärztliche Gespräch wird auf 20 Minuten beschränkt. So fehlt die Empathie und behindert die Entstehung eines Arbeitsbündnisses, der working alliance (R. Greenson). Der vermeintliche Vorteil für den Arzt besteht auch darin, dass er sich die Gefühle vom Leib halten kann, die ein gutes Arbeitsbündnis in ihm auslösen würden. Die unmögliche Formulierung der Qualitätskommission der SGAIM [2] bildet diese Situation ab: Der Arzt soll priorisierend, strukturiert und partizipativ die Entscheidungsfindung durchführen (sic).

In einem kürzlich publizierten VerwaltungsgerichtsUrteil gegenüber einem Arzt, der Geld an die Krankenkasse zurückerstatten soll, wird festgehalten, er habe keine Alltagssorgen zu besprechen, keine Anteilnahme auszusprechen, Patienten auf deren Wunsch hin nicht zu beraten und zu bedauern, keine Zuwendung auszusprechen und keine Lebensberatung zu erteilen (damit sind wir beim Kunden).

\section{Schlussfolgerungen}

Der Patient ist kein Kunde. Weder im Spital, beim Haus- noch beim Spezialarzt. Ihn als Kunden zu bezeichnen schliesst das Psycho-Soziale aus, das wie das Biologische zur Natur des Menschen gehört, eingeschlossen die Beziehung zwischen Patient und Arzt.

Ein modernes Forschungsgebiet, die Epigenetik, lässt erkennen, wie psychische und soziale Faktoren im Menschen wirken, und zwar bis auf die Ebene der Gene. Ihre Aktivität oder Blockierung wird durch diese Faktoren moduliert.

Es gilt also, die Ärzte schon in ihrer Studentenzeit in der Erfassung und der Integration biologischer, psychischer und sozialer Gegebenheiten auszubilden. Damit ist keineswegs ein eigenes Fachgebiet Psychosomatik gemeint, sondern die Notwendigkeit der Integration biologischer, psychischer und sozialer Faktoren in die Medizin.

Die Weiterentwicklung der Technik in der Medizin darf nicht ein Weniger, sondern soll im Gegenteil ein Mehr an Berücksichtigung der psychosozialen Aspekte bringen.

\section{Referenzen}

1 Adler RH. Qualitätskontrolle zeugt von fehlendem Vertrauen. Schweiz. Ärzteztg. 2018;99:882.

2 Brühwiler J. Replik auf den Leserbrief von Prof. Adler. Schweiz. Ärzteztg. 2018;99:882-3. 